\title{
Individual differences in long-term memory access
}

\author{
EARL B. HUNT, JANET DAVIDSON, and MARCY LANSMAN \\ University of Washington, Seattle, Washington 98195
}

\begin{abstract}
In a study of individual differences in long-term memory access, university undergraduates verified (1) whether an item was a member of a category, (2) whether two items belonged to the same category, and (3) whether two words had the same name. Reaction times from these tasks were correlated with verbal ability, as measured by performance on a standardized test of vocabulary and reading comprehension. A relationship was found between verbal ability and reaction time in the verification tasks. These results are contrasted with those of Hogaboam and Pellegrino (1978), who failed to find such a relationship. The results indicated that the various reaction time measures form a single factor that bears a moderate relationship to reading and vocabulary measures.
\end{abstract}

Written language depends on the arbitrary connection of symbols with their referents. There is no particular reason why the symbols " $A$ " and "a" should refer to the first letter of the alphabet. Similarly, there is no reason why "cat" should be the linguistic symbol for a small, domesticated feline. We simply have to memorize the associations that our language uses. In the last 10 years, there have been several studies indicating that the speed of retrieving such associations is a stable dimension of individual differences and that this dimension bears a moderate, but reliable, statistical relationship to scores on conventional written aptitude tests. The correlation is -.3 (long retrieval times are associated with low aptitude) in homogeneous groups of subjects, such as college students. The absolute differences in retrieval times may be considerable if one compares groups of widely varying abilities, such as normal young adults and educable mental retardates (Hunt, 1978, 1981).

Much of the evidence for the assertion that name retrieval is related to verbal aptitude is based upon studies using some variant of the stimulus matching paradigm developed by Posner and Mitchell (1967). In the stimulus matching paradigm, the subject is presented two visual symbols and asked to indicate whether or not they name the same item. Examples are the letter pair A-A, which is a physically identical ( $\mathrm{Pl}$ ) pair, and $\mathrm{A}-\mathrm{a}$, which is a name-identical $(\mathrm{NI})$ pair. Responses are faster to PI than to NI pairs, and the difference

This research was supported by Grant MH-2179 from the National Institute of Mental Health to the University of Washington. Many of the ideas for the design of this study were inspired by discussions with Steven Schwartz. We are grateful to Simon Farr for suggesting the semantic matching paradigm and for his helpful criticism, and to Steven Yantis for his assistance with the data analysis. Reprints may be requested from Earl Hunt, Department of Psychology, NI-25, University of Washington, Seattle, Washington 98195. between the two types of pairs is smaller in groups of higher verbal ability. Indeed, both name matches and physical matches tend to be faster in higher ability groups, al though time for a name match is more highly correlated with verbal ability measures than is time for a physical match (Hunt, Lunneborg, \& Lewis, 1975).

The fact that performance in the stimulus matching paradigm is tied to verbal aptitude is not, in itself, of great interest. Interest arises from the interpretation of the paradigm. If reaction time in the stimulus matching paradigm is a measure of speed of retrieval of overlearned information, then the association of retrieval speed with verbal aptitude gives us information about the processing that underlies a complex talent. But is this interpretation of the task appropriate? As is virtually always the case in experimental psychology, several models have been proposed to explain performance in this task (Posner, 1978). Thus, in order to buttress the theoretical conclusion, it would be desirable to show that other measures of the speed of access to overlearned semantic information are correlated with verbal ability.

Hogaboam and Pellegrino (1978) attempted to do just this. They used a semantic categorization task in which observers were first told a category name and then were presented a sequence of nouns and line drawings. The task was to indicate whether each item in the sequence was an exemplar or a nonexemplar of the category. Hogaboam and Pellegrino found (as had other investigators) that reaction time for categorization was a function of stimulus type, frequency of occurrence of the stimulus as an exemplar of its category, and type of decision (positive or negative). However, they did not find any relationship between category identification time and verbai rility as measured by the Scholastic Aptitude Test (SAT). Hogaboam and Pellegrino concluded that previous findings based on the stimulus matching paradigm might not be due to individual differences in the process of retrieving a name from 
memory. They argued instead that the previous findings might have been due to more intelligent subjects' being more adept at responding to the unusual task demands of the stimulus matching paradigm.

Hogaboam and Pellegrino (1978) raised an important issue. If the results obtained from the stimulus matching paradigm are due to task demands, rather than to the retrieval of information from memory, the previous results should be reinterpreted.(Indeed, the phenomenon of individual differences in adjustment to task demands would itself be worth explanation.) Before drawing this conclusion, however, we wished to replicate the empirical findings reported by Hogaboam and Pellegrino. In particular, certain aspects of their statistical treatment and their interpretation of the semantic categorization paradigm raised some questions.

To summarize Hogaboam and Pellegrino's (1978) argument, they observed that (1) measures derived from the semantic categorization task were sufficiently reliable to produce the nomothetic effects (e.g., effects of taxonomic category and frequency) observed by others, but (2) these measures were not significantly correlated with measures of verbal ability. They concluded that, because the semantic categorization task certainly requires subjects to access semantic information in long-term memory, the failure to find significant correlations is evidence against a relationship between speed of access to semantic information and verbal ability.

Schwartz (1981) has questioned Hogaboam and Pellegrino's (1978) theoretical interpretation of their semantic categorization paradigm. The procedure required the subject to memorize a category name (e.g., BIRD) and then determine whether 24 stimuli were exemplars or nonexemplars of that category. Thus, the subject was asked to hold the category name in short-term memory while responding to the items to be categorized. This differs from the stimulus matching procedure, in which short-term memory requirements are much reduced. It has been observed that short-term memory performance does not correlate with verbal ability scores, except when the contrast is between widely separated groups, such as university students and mental retardates (Hunt, 1978; see also Matarazzo, 1972, for a discussion of some psychometric evidence). Schwartz argued that short-term memory requirements in the semantic categorization task may have affected the observed pattern of individual differences. Another complicating fact is that some of Hogaboam and Pellegrino's measures involved the categorization of pictures.

Because Hogaboam and Pellegrino (1978) did not observe correlations between verbal ability and semantic categorization, they concluded that the correlation between verbal ability and stimulus matching was due to special aspects of the stimulus matching task that do not involve access to name codes. An alternative explanation is that the failure to observe correlations between verbal ability and the semantic categorization task might be due to the introduction of information processing requirements into the semantic categorization task that do not appear in stimulus matching and that are not associated with verbal ability.

Quite aside from theoretical issues, the Hogaboam and Pellegrino (1978) experiment is basically a report of a lack of statistical relation. In order to evaluate null results, issues of reliability and statistical power must be addressed. In their paper, Hogaboam and Pellegrino (1978) did not provide either the values of the (nonsignificant) correlations or the reliabilities of their measures of individual performance.

In order to resolve these issues, Hogaboam and Pellegrino's (1978) study was replicated and extended. The number of subjects was increased to address the issue of statistical power. In addition, the number of trials contributing to each measure was increased, and data were collected on the reliability of the measures. Finally, the short-term memory demands of the experimental tasks were manipulated to test Schwartz's (1981) hypothesis.

\section{METHOD}

The experiment consisted of three phases. In the first phase, Hogaboam and Pellegrino's (1978) experimental procedure was replicated as exactly as possible, based on the information in their published report. In the second phase, subjects completed additional trials in the Hogaboam and Pellegrino semantic categorization task in order to increase the reliability of the reaction time measures. Finally, a number of other experimental tasks were administered in an effort to examine more carefully the differences between the semantic categorization and the stimulus matching paradigms. In these additional tasks, the short-term memory demands and the nature of the yes-no decision were both varied.

Hogaboam and Pellegrino (1978) used the verbal score from the SAT as their criterion measure of verbal ability. Some of our subjects had verbal scores on the Washington Pre-College (WPC) test, which is similar to the SAT. However, since college entrance examination scores were not available for all of our subjects, our criterion measure was the Nelson-Denny Reading Test (Nelson \& Denny, 1960), which provides measures of reading rate, vocabulary, and reading comprehension. High correlations have been found between the Nelson-Denny Test and verbal scores on the WPC (Palmer, MacLeod, Hunt, \& Davidson, Note 1).

\section{Subjects}

The subjects were 75 University of Washington undergraduates (28 males and 47 females). They were paid $\$ 15$ for their participation. Subjects were run in groups of two to six. Due to attrition and computer failure, data were not obtained on all measures from all subjects.

\section{Apparatus}

A NOVA 3 computer controlled stimulus presentation and response collection for the reaction time tasks. During Session 1 , which involved presentation of both words and pictures, subjects were seated at individual desks that held response keyboards. Slides were projected by a Kodak Carousel $850 \mathrm{H}$ slide projector onto an $8 \times 8 \mathrm{ft}$ white screen viewed by all subjects in the group. 
Pioneer SE20A 8 I headphones were used for auditory feedback. During Sessions 2 and 3, subjects were seated in individual sound-attenuating booths. Each booth contained a response keyboard and an independently-controlled Tektronix 604 cathode-ray tube oscilloscope on which the stimuli were presented.

\section{Procedure}

Subjects participated in three $1.5 \mathrm{~h}$ sessions. All subjects performed the same tasks in the same order. Table 1 shows the order of task presentation.

For all tasks, subjects were told to work as quickly as possible without making errors. Feedback was provided for the reaction time tasks. During Session 1, subjects heard a tone whenever they made an error. During Sessions 2 and 3, subjects received "OK" or "No" messages on their screens, after each trial, informing them of the accuracy of their responses. In addition, during Sessions 2 and 3, after every set of eight trials subjects saw their reaction times in milliseconds averaged over those eight trials, and the total number of errors they had made so far. If they wished, subjects could relax for a moment in their booths at this time. When they were ready to begin the next set of eight trials, they pressed any key on their response boards and the next trial began $250 \mathrm{msec}$ later. Thereafter, trials were spaced $500 \mathrm{msec}$ after trial feedback. Every trial was preceded by a warning dot that appeared for $250 \mathrm{msec}$ in the center of the screen. There was a $250-\mathrm{msec}$ interval between the offset of the warning dot and the onset of the stimulus.

\section{Session 1}

Semantic categorization. This task, which was a replication of Hogaboam and Pellegrino's (1978) procedure, was performed at the beginning and end of Session 1. Subjects were asked to determine whether an item belonged to a specified semantic category. For example, they might be asked to respond as to whether a car is a vehicle. As in the Hogaboam and Pellegrino study, the furniture category was used for practice trials and the experimental categories were carpenter's tools, vehicles, body parts, four-legged animals, weapons, articles of clothing, kitchen utensils, musical instruments, insects, and fruits. Three high- and three low-taxonomic-frequency items from each of the experimental categories were selected from the Battig and Montague (1969) norms. The average taxonomic frequency was 308 for the high-frequency items and 32 for the low-frequency items. (Hogaboam and Pellegrino's average frequencies were 350 and 34, respectively.) The Kucera and Francis (1967) average printed frequency was 64.1 for the high-frequency items and 3.3 for the low-frequency items. (Hogaboam and Pellegrino's average printed frequencies were 84 and 4.5 for high and low items, respectively.) Each item was depicted as an unambiguous line drawing and as an uppercase printed word. Slides were made of the drawing and words. Slides were also made of each category name printed in uppercase letters and underlined.

A block of trials consisted of a category name followed by 24 items. Twelve of the items were exemplars and 12 were not. The positive items (exemplars) were three high- and three low-taxonomic-frequency members of the category, each presented once as a word and once as a picture. Negative items for the practice block were taken from categories not used in this experiment. Negative items for the first five categories were taken from the positive items of the last five categories. Negative items for the last five experimental categories were taken from the positive items of the first five categories. The 12 negative items in each block consisted of three items of high taxonomic frequency in their own categories and three items of low taxonomic frequency. Items were represented as both pictures and words. Half of the subjects saw one set of five categories first, and the other half of the subjects saw the other set of five categories first. The order of categories within each set of five categories was varied for each group of subjects according to a Latin square design.

Each category name was displayed for $3,000 \mathrm{msec}$. Each item was displayed for $1,000 \mathrm{msec}$. Subjects were instructed to press the right key if an item was a member of the category and the left key if it was not. Subjects heard a tone through headphones whenever they made an error.

Nelson-Denny vocabulary test. Form B of the vocabulary portion of the Nelson-Denny (1960) test was administered. Subjects were given $10 \mathrm{~min}$ to answer 100 items. Subjects were instructed to select the best definition of a word from among five choices. Responses were recorded on the Nelson-Denny self-marking answer sheet.

Nelson-Denny reading test. Form B of the comprehension and reading rate portion of the Nelson-Denny (1960) test was administered. Subjects were given $20 \mathrm{~min}$ to read eight selections and answer multiple-choice questions at the end of each selection. While answering questions, subjects were allowed to refer to the relevant passage. If they had difficulty with a question, they were told to make a reasonable effort and then go on to the next question. Subjects used the Nelson-Denny self-marking answer sheet to record their responses.

The first $1 \mathrm{~min}$ of the test was used to determine reading rate. Subjects began reading the passage, and, at the end of

Table 1

Schedule of Tasks

\begin{tabular}{lll}
\hline \multicolumn{1}{c}{ Session 1 } & \multicolumn{1}{c}{ Session 2 } & \multicolumn{1}{c}{ Session 3 } \\
\hline Semantic Categorization & Two-Choice Reaction Time & Two-Choice Reaction Time \\
Nelson-Denny & Word Matching & Semantic Matching \\
Vocabulary & Simultaneous Presentation of Stimuli & Sequential Presentation of Stimuli \\
Nelson-Denny & Word Matching & Semantic Matching \\
Reading Comprehension & Sequential Presentation of Stimuli & Simultaneous Presentation of Stimuli \\
Paper-and-Pencil & Semantic Verification & Semantic Verification \\
Sentence-Picture Comprehension & Simultaneous Presentation of Stimuli & Sequential Presentation of Stimuli \\
Semantic Categorization & Semantic Verification & Semantic Verification \\
& Sequential Presentation of Stimuli & Simultaneous Presentation of Stimuli \\
& Semantic Matching & Word Matching \\
& Simultaneous Presentation of Stimuli & Sequential Presentation of Stimuli \\
& Semantic Matching & Word Matching \\
& Sequential Presentation of Stimuli & Simultaneous Presentation of Stimuli \\
\hline
\end{tabular}


$1 \mathrm{~min}$, they were told to stop on the line they were reading and record that line number on their answer forms. When this was completed, subjects resumed their reading.

Sentence-picture comprehension test. This paper-and-pencil test is divided into five sections (Lansman, Note 2). Because of time restraints, only the first three sections were administered. Section 1 was considered practice. Each section contains 64 items. For each item, subjects were asked to determine whether a sentence accurately described a picture (Clark \& Chase, 1972). The stimuli consisted of 16 descriptive sentences that varied in linguistic complexity (e.g., plus above star; star isn't above plus) and two pictures $\left({ }_{*}^{+} ; \underset{+}{*}\right)$. If the sentence correctly described the picture, subjects were to mark the $T$ for true; otherwise, they were to mark the $F$ for false. Subjects were given $2.5 \mathrm{~min}$ for each of the three sections.

The sentence-picture comprehension task provided a logical verbal task that, presumably, depends less upon access to the meaning of words than the other tasks. Obviously, a person doing a sentence-picture comprehension task must know what the words mean. However, only six words are used in this task. Thus it is more dependent upon the manipulation of verbal items in working memory (Baddeley, 1976) than upon the retrieval of information about the names of the stimuli. In a previously conducted analysis of the information processing correlates of reading, we found that sentence verification and stimulus matching were predictors of different components of reading skill: Sentence-picture comprehension was more related to reading comprehension, and stimulus matching was more related to reading speed (Palmer et al., Note 1). Thus, we might expect the semantic tasks and the sentence-picture comprehension task to make independent contributions to the prediction of verbal ability scores.

\section{Session 2}

Two-choice reaction time. A simple choice reaction time task was given in order to familiarize subjects with the apparatus and to obtain a basic measure of keypressing time. On each trial of this task, subjects saw three stars on the screen to either the left or the right of center. They pressed the right key if stars were on the right and the left key if stars were on the left. There were eight practice trials and 48 experimental trials.

Stimulus (word) matching. This task required subjects to determine whether two words had the same name (Palmer et al., Note 1). The stimuli were pairs of common four-letter words. The "different" trials consisted of word pairs differing by one letter (e.g., DATE-GATE), with the discrepant letter balanced over position. The words were presented in upper- and lowercase. There were 24 PI pairs (DATE-DATE), 24 NI pairs (DATE-date), and 48 different pairs (date-gate). Each pair was shown twice. Subjects were to respond "same" by pressing the right key if the words had the same name and to respond "different" by pressing the left key if the words had different names.

In the simultaneous condition of this task, the words appeared side by side on the screen with one character space between words. The word pairs remained on the screen until the subject responded. There were 16 practice trials and 192 experimental trials of this condition.

In the sequential condition, devised to add a short-term memory component, one word appeared on the screen for $500 \mathrm{msec}$. Then, $1,500 \mathrm{msec}$ later, the second word appeared and remained on the screen until the subject responded. There were 16 practice trials and 192 experimental trials.

Semantic verification. This task, like the semantic categorization task, required subjects to determine whether an item was a member of a category. A category name and an item were presented on each trial. All stimuli were presented as uppercase words. Subjects were to press the right key if the item was a member of the category; otherwise, they were to press the left key.
The category names and items used in this task were a subset of those used in the semantic categorization task. The eight experimental categories were furniture, body part, fruit, weapon, clothing, insect, vehicle, and animal. Three instances of high taxonomic frequency and three instances of low taxonomic frequency were selected from each category. Each instance appeared once as a positive item and once as a negative item.

In the simultaneous condition, the category name and the item appeared on the screen at the same time. The category name was directly above the item, and both pieces of information remained on the screen until the subject responded. There were 16 practice trials and 96 experimental trials.

In the sequential presentation condition, the category name appeared on the screen for $500 \mathrm{msec}$, and $1,500 \mathrm{msec}$ later the item appeared. The item remained on the screen until the subject responded. There were 16 practice trials and 96 experimental trials.

Semantic matching. The semantic categorization and the semantic verification tasks involve making decisions about superordinate-subordinate (category-instance) relationships, whereas the stimulus matching task involves making a subordinatesubordinate, or "instance-instance," decision. The semantic matching task required the subject to make a semantic decision about two instances. On each trial of this task, subjects had to decide whether two items were members of the same category (Goldberg, Schwartz, \& Stewart, 1977). Subjects were to press the right key if the two items belonged in the same category (APPLE-PEACH); otherwise, they were to press the left key (APPLE-PLANE). All stimuli were presented in uppercase letters. Four instances of high taxonomic frequency and four instances of low taxonomic frequency were selected from the following categories: vehicle, fruit, body part, furniture, insect, and clothing. Each instance appeared twice as a positive item and twice as a negative item. Instances of high taxonomic frequency were paired together and instances of low taxonomic frequency were paired together; there were no instances of high taxonomic frequency paired with instances of low taxonomic frequency.

In the simultaneous presentation condition, two items appeared on the screen at the same time, with one item centered directly above the other. Both items remained on the screen until the subject responded. There were 16 practice trials and 96 experimental trials.

In the sequential presentation condition, one item appeared on the screen for $500 \mathrm{msec}$ and, $1,500 \mathrm{msec}$ later, the second item appeared. The second item remained on the screen until the subject responded. There were 16 practice trials and 96 experimental trials.

\section{Session 3}

Subjects performed the same tasks during Session 3 that they performed during Session 2. The two-choice reaction time task was presented first, and the others were presented in reverse order from Session 2.

\section{RESULTS}

The results section is divided into three parts. The first part is a general description of the data. The second presents the group results for each task. The third part is a discussion of the individual differences results.

\section{General Description}

The mean reaction time for each trial type was calculated for each subject. Data were analyzed only for trials on which the response was correct and on which reaction times were within 3 standard deviations of the mean for that subject in that condition. 
Split-half reliabilities (odd vs. even trials) were calculated for correct reaction times and corrected using the Spearman-Brown formula. All mean reaction time measures were highly reliable, with reliabilities ranging from .94 to .99 .

Each reaction time task was presented twice. Because the same experimental effects were observed on each occasion, data from the two presentations were combined for each task, with the exception of the semantic categorization task, in order to increase the number of observations.

\section{Group Results}

Semantic categorization. The semantic categorization task was presented twice, once in an exact replication of Hogaboam and Pellegrino's (1978) procedure and then again to increase the reliability of the data. For each presentation of this task, mean reaction times were calculated for each subject for each combination of stimulus type (words, pictures), taxonomic frequency (high, low), and decision type (yes, no). Table 2 shows the mean reaction times for these measures.

The results from both presentations of this task replicated the main results found by Hogaboam and Pellegrino (1978). Positive decisions were faster than negative decisions, category membership of pictures was verified faster than membership of words, and items of high taxonomic frequency were verified faster than items of low taxonomic frequency $(p<.001$ for these comparisons).

Semantic verification (FRUIT-APPLE) and semantic matching (APPLE-PEACH). The results from each of these tasks were similar to those found in the semantic categorization task. Positive decisions were faster than negative decisions, and items of high taxonomic frequency were verified faster than items of low taxonomic frequency ( $p<.001$ for these comparisons). The mean reaction times from the semantic verification task and the semantic matching task are shown in Table 3.

Stimulus matching (DATE-date). Reaction times from this task are shown in Table 4. In the simultaneous condition, mean PI reaction time was $121 \mathrm{msec}$ faster than mean NI reaction time. Differences of approximately this size have been found in previous studies. In the sequential condition, the difference between $\mathrm{NI}$ and

Table 2

Mean Reaction Time for Correct Responses to Each Stimulus Type for Each Presentation of the Semantic Categorization Task

\begin{tabular}{cccccccc}
\hline \multicolumn{2}{c}{ Stimulus } & & \multicolumn{2}{c}{ Time 1 } & & \multicolumn{2}{c}{ Time 2 } \\
\cline { 7 - 8 } \cline { 6 - 7 } Frequency & Type & & P & N & & P & N \\
\hline High & Words & 653 & 703 & 622 & 670 \\
High & Pictures & 637 & 698 & 592 & 672 \\
Low & Words & 711 & 725 & 656 & 694 \\
Low & Pictures & 682 & 720 & 609 & 684 \\
\hline
\end{tabular}

Note $-P=$ positive responses; $N=$ negative responses. Reaction times are given in milliseconds.
Table 3

Mean Reaction Times for Correct Responses to Each Stimulus Type for the Semantic Verification (BIRD-ROBIN) and Semantic Matching (ROBIN-SPARROW) Tasks

\begin{tabular}{|c|c|c|c|c|c|}
\hline \multicolumn{2}{|c|}{ Stimulus } & \multicolumn{2}{|c|}{$\begin{array}{c}\text { Semantic } \\
\text { Verification }\end{array}$} & \multicolumn{2}{|c|}{$\begin{array}{l}\text { Semantic } \\
\text { Matching }\end{array}$} \\
\hline Frequency & Presentation & $\mathbf{P}$ & $\mathbf{N}$ & $\mathbf{P}$ & $\mathbf{N}$ \\
\hline High & Simultaneous & 757 & 862 & 743 & 861 \\
\hline Low & Simultaneous & 789 & 867 & 775 & 854 \\
\hline High & Sequential & 561 & 638 & 536 & 597 \\
\hline Low & Sequential & 589 & 639 & 557 & 598 \\
\hline
\end{tabular}

Note $-P=$ positive responses; $N=$ negative responses. Reaction times are given in milliseconds.

Table 4

Mean Reaction Time for Correct Responses to Each Stimulus Type for the Stimulus Matching Task

\begin{tabular}{lcc}
\hline \multicolumn{1}{c}{ Stimulus Type } & \multicolumn{2}{c}{ Presentation } \\
\cline { 2 - 3 } & $\begin{array}{c}\text { Simul- } \\
\text { taneous }\end{array}$ & $\begin{array}{c}\text { Sequen- } \\
\text { tial }\end{array}$ \\
\hline Name-Identical Words (NI) & 700 & 497 \\
Physically Identical Words (PI) & 579 & 478 \\
Different Words in the Same Case & 707 & 542 \\
Different Words in Different Cases & 729 & 544 \\
\hline
\end{tabular}

Note $-N=69$ for each of the two presentation conditions. Reaction times are given in milliseconds.

PI reaction times was much smaller $(19 \mathrm{msec})$. The finding of a smaller difference between NI and PI reaction times when stimuli are presented sequentially is also a very common result. It has been attributed to the fact that, when there is a delay between the two items in a pair, the physical match, as well as the name match, must be made on the basis of the names of the stimuli, since the visual trace of the initial item has faded by the time the second item appears (Posner, 1978).

Two-choice reaction time. The mean reaction time for right-hand responses on correct trials was 276 msec. The mean reaction time for left-hand responses on correct trials was $287 \mathrm{msec}$.

Paper-and-pencil tests. Table 5 shows the mean scores for number correct, standard deviations, and range of scores for the Nelson-Denny vocabulary, Nelson-Denny reading comprehension, and sentencepicture comprehension tests.

\section{Individual Differences}

Hogaboam and Pellegrino (1978) reported eight processing speed measures: the time to categorize items representing the eight possible combinations of high and low frequency, pictures and words, and positive and negative decisions. In our data, the reliabilities of these measures were high. Split-half reliabilities, based on odd vs. even trials, ranged from .92 to .97 . Table 6 shows the correlations between these eight measures and the four measures taken on the Neison-Denny test: 
Table 5

Descriptive Statistics for the Psychometric Measures

\begin{tabular}{lcrrrr}
\multicolumn{1}{c}{ Measure } & $\begin{array}{c}\text { Mean Number } \\
\text { Correct }\end{array}$ & $\begin{array}{c}\text { Reading } \\
\text { Rate }\end{array}$ & SD & Range & N \\
\hline Nelson-Denny Vocabulary & 58 & & 15 & $27-98$ & 74 \\
Nelson-Denny Reading Comprehension & 27 & 6 & $8-36$ & 74 \\
Nelson-Denny Reading Rate & & 301 & 95 & $117-615$ & 74 \\
Sentence-Picture Comprehension & 44 & & 10 & 75 \\
\hline
\end{tabular}

Note-Reading rates are given in words per minute.

Table 6

Correlations Between Processing Speed Measures and Verbal Measures

\begin{tabular}{|c|c|c|c|c|c|c|}
\hline \multirow[b]{2}{*}{ Processing Speed Measures } & \multirow[b]{2}{*}{$\begin{array}{l}\text { Reli- } \\
\text { ability }\end{array}$} & \multicolumn{4}{|c|}{ Nelson-Denny } & \multirow[b]{2}{*}{ WPC } \\
\hline & & Composite & Vocabulary & $\begin{array}{c}\text { Reading } \\
\text { Comprehension }\end{array}$ & $\begin{array}{l}\text { Reading } \\
\text { Rate }\end{array}$ & \\
\hline & \multicolumn{6}{|c|}{ Time 1} \\
\hline $\begin{array}{l}\text { High Frequency, Positive Responses, Words } \\
\text { High Frequency, Negative Responses, Words } \\
\text { High Frequency, Positive Responses, Pictures } \\
\text { High Frequency, Negative Responses, Pictures } \\
\text { Low Frequency, Positive Responses, Words } \\
\text { Low Frequency, Negative Responses, Words } \\
\text { Low Frequency, Positive Responses, Pictures } \\
\text { Low Frequency, Negative Responses, Pictures }\end{array}$ & $\begin{array}{l}.95 \dagger \\
.96 \dagger \\
.96 \dagger \\
.93 \dagger \\
.94 \dagger \\
.95 \dagger \\
.95 \dagger \\
.94 \dagger\end{array}$ & $\begin{array}{l}-.21 \\
-.24^{*} \\
-.13 \\
-.28^{*} \\
-.29^{*} \\
-.29^{*} \\
-.28^{*} \\
-.31 \dagger\end{array}$ & $\begin{array}{l}-.15 \\
-.20 \\
-.08 \\
-.23^{*} \\
-.22 \\
-.25^{*} \\
-.20 \\
-.25^{*}\end{array}$ & $\begin{array}{l}-.25^{*} \\
-.26^{*} \\
-.18 \\
-.29^{*} \\
-.32 \dagger \\
-.30^{*} \\
-.33 \dagger \\
-.34 \dagger\end{array}$ & $\begin{array}{r}.07 \\
-.07 \\
.03 \\
-.08 \\
.02 \\
-.05 \\
.00 \\
-.02\end{array}$ & $\begin{array}{r}.01 \\
.02 \\
.09 \\
-.09 \\
.01 \\
-.01 \\
.04 \\
.02\end{array}$ \\
\hline \multirow[t]{2}{*}{ Number of Subjects } & 55 & 54 & 54 & 54 & 54 & 26 \\
\hline & \multicolumn{6}{|c|}{ Time $1+$ Time 2} \\
\hline $\begin{array}{l}\text { High Frequency, Positive Responses, Words } \\
\text { High Frequency, Negative Responses, Words } \\
\text { High Frequency, Positive Responses, Pictures } \\
\text { High Frequency, Negative Responses, Pictures } \\
\text { Low Frequency, Positive Responses, Words } \\
\text { Low Frequency, Negative Responses, Words } \\
\text { Low Frequency, Positive Responses, Pictures } \\
\text { Low Frequency, Negative Responses, Pictures }\end{array}$ & $\begin{array}{l}.98 \dagger \\
.98 \dagger \\
.97 \dagger \\
.97 \dagger \\
.97 \dagger \\
.98 \dagger \\
.98 \dagger \\
.97 \dagger\end{array}$ & $\begin{array}{l}-.27^{*} \\
-.28^{*} \\
-.19 \\
-.29^{*} \\
-.29^{*} \\
-.27^{*} \\
-.28^{*} \\
-.28^{*}\end{array}$ & $\begin{array}{l}-.18 \\
-.20 \\
-.12 \\
-.22 \\
-.21 \\
-.21 \\
-.19 \\
-.21\end{array}$ & $\begin{array}{l}-.32 \dagger \\
-.33 \dagger \\
-.25 \\
-.33 \dagger \\
-.33 \dagger \\
-.30^{*} \\
-.36 \dagger \\
-.32 \dagger\end{array}$ & $\begin{array}{r}.03 \\
-.05 \\
.03 \\
-.05 \\
.02 \\
-.04 \\
.01 \\
.00\end{array}$ & $\begin{array}{l}-.15 \\
-.17 \\
-.06 \\
-.24 \\
-.18 \\
-.16 \\
-.09 \\
-.12\end{array}$ \\
\hline Number of Subjects & 52 & 51 & 51 & 51 & 51 & 25 \\
\hline
\end{tabular}

Note-WPC $=W P C$ verbal composite. $\quad * p<.05 \quad t_{p}<.01$

vocabulary, paragraph comprehension, reading rate, and a composite score. (Nelson and Denny's suggested composite $=2 \times$ comprehension + vocabulary.) The upper half of Table 6 shows the correlations based on the same number of trials used by Hogaboam and Pellegrino. The lower half shows correlations based on reaction times from both presentations of the semantic categorization task. Thus the upper half of the table can be considered a replication of the Hogaboam and Pellegrino procedure, and the lower half a replication using twice the number of trials.

Consider first the upper half of the table. The eight correlations of reaction time measures with the NelsonDenny composite range from -.14 to -.31 . Six of the eight are statistically significantly different from 0 at the .05 level. The correlations based on additional data are shown in the lower half of the table. Seven of the eight are statistically significant. Clearly, these results are more consistent with the hypothesis that the population correlation is -.3 than with the hypothesis that it is 0 .
This statement can be quantified by calculating the following likelihood ratio: (probability of $r$ given that population $r=-.3$ ) divided by (probability of $r$ given that population $r=0$ ). For $r=-.25$ and $n=67$, typical of data in Table 5, the ratio is greater than $6: 1$ in favor of the hypothesis $r=-.3$.

Hogaboam and Pellegrino (1978) also computed eight difference scores that represented word-picture differences for high- and low-frequency positive and negative items and low-/high-frequency differences for positive and negative pictures and words. The relevant results from our study are shown in Table 7 , which is similar in format to Table 6 . The reliabilities of the difference scores were low, and one is even negative. With such low reliabilities, it is hardly surprising to find that there were few significant correlations with the Nelson-Denny measures.

In summary, the individual differences data presented here would not lead one to the negative conclusion drawn by Hogaboam and Pellegrino (1978). A relation- 
Table 7

Correlations Between Processing Speed Difference Scores and Verbal Measures

\begin{tabular}{|c|c|c|c|c|c|c|}
\hline \multirow[b]{2}{*}{ Processing Speed Measures } & \multirow[b]{2}{*}{$\begin{array}{l}\text { Reli- } \\
\text { ability }\end{array}$} & \multicolumn{4}{|c|}{ Nelson-Denny } & \multirow[b]{2}{*}{ WPC } \\
\hline & & Composite & $\begin{array}{l}\text { Vocab- } \\
\text { ulary }\end{array}$ & $\begin{array}{l}\text { Reading Com- } \\
\text { prehension }\end{array}$ & $\begin{array}{l}\text { Reading } \\
\text { Rate }\end{array}$ & \\
\hline & \multicolumn{6}{|c|}{ Time 1} \\
\hline Words-Pictures, High Frequency, Positive Responses & $.27^{*}$ & -.17 & -.17 & -.14 & .11 & -.24 \\
\hline Words-Pictures, High Frequency, Negative Responses & $-.26^{*}$ & .20 & .17 & .19 & .06 & $.43^{*}$ \\
\hline Words-Pictures, Low Frequency, Positive Responses & $.33 \dagger$ & .04 & -.02 & .11 & .07 & -.13 \\
\hline Words-Pictures, Low Frequency, Nega tive Responses & .09 & .08 & .03 & .14 & -.06 & -.09 \\
\hline Low-High Frequency, Positive Responses, Words & $.31^{*}$ & $-.31 *$ & $-.28 *$ & $-.30 *$ & -.11 & -.01 \\
\hline Low-High Frequency, Negative Responses, Words & .06 & -.21 & -.20 & -.18 & .07 & -.11 \\
\hline Low-High Frequency, Positive Responses, Pictures & $.48 \dagger$ & $-.41 \dagger$ & $-.33 \dagger$ & $-.44 \dagger$ & -.06 & -.09 \\
\hline Low-High Frequency, Negative Responses, Pictures & .01 & -.08 & -.04 & -.11 & .15 & $.31^{*}$ \\
\hline \multirow[t]{2}{*}{ Number of Subjects } & 55 & 54 & 54 & 54 & 54 & 26 \\
\hline & \multicolumn{6}{|c|}{ Time $1+$ Time 2} \\
\hline Words-Pictures, High Frequency, Positive Responses & .19 & $-.23 *$ & -.21 & -.21 & -.01 & -.31 \\
\hline Words-Pictures, High Frequency, Negative Responses & -.16 & .13 & .14 & .10 & .03 & $.46 \dagger$ \\
\hline Words-Pictures, Low Frequency, Positive Responses & $.37 \dagger$ & -.04 & -.12 & .07 & .06 & $-.35^{*}$ \\
\hline Words-Pictures, Low Frequency, Negative Responses & .17 & -.00 & -.05 & .06 & -.16 & -.16 \\
\hline Low-High Frequency, Positive Responses, Words & $.43 \dagger$ & -.20 & -.18 & -.18 & -.02 & -.18 \\
\hline Low-High Frequency, Negative Responses, Words & .05 & -.05 & -.10 & .04 & .04 & .03 \\
\hline Low-High Frequency, Positive Responses, Pictures & $.35 \dagger$ & $-.38 \dagger$ & $-.28^{*}$ & $-.45 \dagger$ & -.08 & -.12 \\
\hline Low-High Frequency, Negative Responses, Pictures & .16 & .07 & .07 & .06 & .22 & $.49 \dagger$ \\
\hline Number of Subjects & 52 & 51 & 51 & 51 & 51 & 25 \\
\hline
\end{tabular}

Note-WPC $=W P C$ verbal composite. $\quad * p<.05 \quad t_{p}<.01$

Table 8

Correlation Between Nelson-Denny Component Scores and Various Reaction Time Measures for Positive Responses

\begin{tabular}{|c|c|c|c|c|c|c|}
\hline \multirow[b]{2}{*}{ Information Processing Task } & \multirow[b]{2}{*}{$\mathbf{N}$} & \multirow[b]{2}{*}{$\begin{array}{c}\text { Reli- } \\
\text { ability }\end{array}$} & \multicolumn{4}{|c|}{ Nelson-Denny Component Score } \\
\hline & & & Composite & Vocabulary & $\begin{array}{c}\text { Reading } \\
\text { Comprehension }\end{array}$ & $\begin{array}{c}\text { Reading } \\
\text { Rate }\end{array}$ \\
\hline Semantic Categorization & 52 & .99 & $-.28 *$ & -.20 & $-.33 \dagger$ & -.02 \\
\hline Semantic Verification-Simultaneous & 69 & .98 & $-.29+$ & $-.27 *$ & $-.28 *$ & $-.29+$ \\
\hline Semantic Verification-Sequential & 69 & .97 & $-.24^{*}$ & $-.20^{*}$ & $-.25^{*}$ & -.09 \\
\hline Semantic Matching-Simultaneous & 67 & .98 & $-.29 \dagger$ & $-.22 *$ & $-.34 \dagger$ & -.20 \\
\hline Semantic Matching-Sequential & 66 & .98 & $-.30+$ & $-.25^{*}$ & $-.31+$ & -.09 \\
\hline NI-PI RT; Word Matching-Simultaneous & 69 & .81 & $-.25^{*}$ & $-.23^{*}$ & $-.24 *$ & -.20 \\
\hline NI-PI RT; Word Matching-Sequential & 69 & .61 & $-.25^{*}$ & $-.26^{*}$ & $-.20 *$ & -.04 \\
\hline
\end{tabular}

Note-Simultaneous and sequential refer to stimulus presentation. Semantic categorization is the replication of Hogaboam and Pellegrino's (1978) results. $\quad * p<.05 \quad t_{p}<.01$

ship was found between category identification time and verbal ability. There is, however, one major difference between our study and theirs. We were forced to use the Nelson-Denny test as our major criterion measure. Only a small number of subjects (26) who completed our replication of the Hogaboam and Pellegrino procedure had also taken the WPC test, a test similar to the SAT used by Hogaboam and Pellegrino. ${ }^{1}$

Short-term memory: A test of Schwartz's hypothesis. Schwartz (1981) observed that the semantic categorization task contained a short-term memory component: The subject must remember the category name while responding to the stimuli to be categorized. Schwartz noted that short-term memory seems to be only loosely related to psychometrically defined verbal ability. He suggested that the short-term memory component of the categorization task may have introduced additional variance that masked the relation between access to information in long-term memory and verbal ability. Our experiment was designed to test Schwartz's hypothesis by manipulating the short-term memory demands of the task and observing the effects on the correlations with psychometric tests. In the sequential version of each task, the subject was required to hold the first item in memory while responding to the second. This introduced a minimal short-term memory requirement into the task. In the simultaneous versions, the short-term memory component was eliminated.

This short-term memory manipulation did not change the pattern of correlations. Table 8 shows the correlations between the verbal measures and reaction times for positive responses to word items in the seman- 
tic categorization task and for positive responses in the simultaneous and sequential versions of the other semantic tasks. Only positive responses were analyzed, because the models for negative responses are unclear, The table also shows the correlation between NelsonDenny scores and the NI-PI reaction time difference score computed for simultaneous and sequential versions of the stimulus matching task (DATE-date). The correlations of all tasks with the Nelson-Denny composite were all slightly below .3 in absolute magnitude and did not vary in any consistent way with the short-term memory requirement.

The correlations between the reaction time measures and the Nelson-Denny reading rate present a different picture. Tasks involving simultaneous presentation of the items had higher correlations with reading rate. This is not surprising, because subjects were timed for reading more material in the simultaneous version than in the sequential version.

Aside from the correlations with reading rate, however, our data provide no evidence that the short-term memory manipulation affected the relationship between verbal ability and reaction time on any of our tasks. Correlations involving simultaneous and sequential conditions are almost identical. Schwartz's (1981) hypothesis does not seem to explain why Hogaboam and Pellegrino (1978) failed to find correlations with verbal ability.

Evidence for a general "speed of access to long-term memory" factor. Each of the tasks used in this study requires the subject to access semantic or lexical information from long-term memory. Semantic categorization requires that information be accessed about both pictures and words. Similarly, the semantic verification (FRUIT-APPLE) and semantic matching (APPLEPEACH) tasks require extraction of semantic information about word stimuli. Finally, the stimulus matching task requires that lexical, but not semantic, information be accessed. To what extent do these tasks tap a common dimension of individual variation?

To answer this question, we first considered the semantic categorization task. This task involved the classification of both words and pictures. We expected that measures based on these two types of stimuli might reflect distinct abilities and thus be only weakly correlated. To our surprise, the correlation between performance on picture stimuli and performance on word stimuli was .99 . This finding is consistent with Hogaboam and Pellegrino's (1978) data. Obviously, measures based on picture and word stimuli can be used interchangeably in our statistical analyses.

We next asked whether or not the different measures of memory access formed a unitary dimension. This was done by submitting reaction times for positive responses in each of the various information processing tasks to a principal-components factor analysis (Harman, 1976). The variables utilized are listed in the correlation matrix shown in Table 9. In order to make the measures comparable, the NI-PI difference score was replaced by the NI reaction time score. The analysis was actually done twice, once on the first-order correlations shown above the diagonal of Table 9 and once on the partial correlations from which the effects of choice reaction time have been removed. The partial correlations are shown below the diagonal of Table 9. Partial correlations were used to provide a control for the possibility that a common factor would appear that was actually defined by the ability to manipulate the equipment. The results of the two analyses were virtually identical. In each case, a single factor was extracted; it accounted for more than $75 \%$ of the common variance and had an eigenvalue greater than 5 . The eigenvalues of the remaining factors were all substantially less than 1 . Table 10 shows, for each analysis, the communalities and factor loadings of the information processing measures on the factor. These results indicate that the different memory-access tasks tap a single common factor, and this factor is not an apparatus factor. An additional point of interest is that the unrotated factor is well defined by either the semantic verification task (FRUIT-APPLE) or the semantic matching task (APPLEPEACH); both have loadings of about .9 on the common factor. ${ }^{2}$

In an extension of this analysis, we asked whether common factors underlying the reaction time tasks were related to common factors involved in the verbal tasks. A canonical correlation was done to answer this question (Cohen \& Cohen, 1975). The first canonical

Table 9

Correlations Used in the Principal Components Analysis

\begin{tabular}{|c|c|c|c|c|c|c|c|}
\hline \multirow[b]{2}{*}{ Information Processing Tasks } & \multicolumn{7}{|c|}{ Positive Responses } \\
\hline & 1 & 2 & 3 & 4 & 5 & 6 & 7 \\
\hline $\begin{array}{l}\text { 1. Semantic Categorization } \\
\text { 2. Semantic Verification-Simultaneous Presentation } \\
\text { 3. Semantic Verification-Sequential Presentation } \\
\text { 4. Semantic Matching-Simultaneous Presentation } \\
\text { 5. Semantic Matching-Sequential Presentation } \\
\text { 6. NI, Word Matching-Simultaneous Presentation } \\
\text { 7. NI, Word Matching-Sequential Presentation }\end{array}$ & $\begin{array}{l}.39 \\
.33 \\
.34 \\
.37 \\
.43 \\
.42\end{array}$ & $\begin{array}{l}.58 \\
.67 \\
.81 \\
.73 \\
.67 \\
.59\end{array}$ & $\begin{array}{l}.53 \\
.80 \\
.71 \\
.85 \\
.45 \\
.74\end{array}$ & $\begin{array}{l}.50 \\
.92 \\
.76 \\
.85 \\
.56 \\
.69\end{array}$ & $\begin{array}{l}.47 \\
.77 \\
.87 \\
.79 \\
.46 \\
.74\end{array}$ & $\begin{array}{l}.58 \\
.79 \\
.69 \\
.74 \\
.65 \\
.67\end{array}$ & $\begin{array}{l}.51 \\
.75 \\
.79 \\
.73 \\
.82 \\
.79\end{array}$ \\
\hline
\end{tabular}

Note-The upper right diagonal shows the raw correlations. The lower left diagonal shows the correlations after choice reaction time has been partialled out. 
Table 10

Communalities and Factor Loadings for Information Processing Variables, Based on Analysis of Original ("First-Order") Correlations and on Partial Correlations Removing Variance Associated With Choice Reaction Time

\begin{tabular}{|c|c|c|c|c|}
\hline \multirow{2}{*}{$\begin{array}{l}\text { Positive Responses } \\
\text { Information Processing Variables }\end{array}$} & \multicolumn{2}{|c|}{ First-Order Analysis } & \multicolumn{2}{|c|}{ Partial Correlation Analysis } \\
\hline & Communality & Factor Loading & Communality & Factor Loading \\
\hline Category Verification & .39 & .60 & .38 & .59 \\
\hline Semantic Verification-Simultaneous Presentation & .89 & .93 & .85 & .90 \\
\hline Semantic Verification-Sequential Presentation & .81 & .89 & .80 & .89 \\
\hline Semantic Matching-Simultaneous Presentation & .87 & .89 & .84 & .89 \\
\hline Semantic Matching-Sequential Presentation & .83 & .87 & .87 & .88 \\
\hline NI, Word Matching-Simultaneous Presentation & .75 & .84 & .79 & .79 \\
\hline NI, Word Matehing-Sequential Presentation & .79 & .88 & .78 & .85 \\
\hline
\end{tabular}

correlation was .69 and was significant at the .02 level. (The canonical analysis was based on the 52 subjects, for whom all data were available.) The remaining two canonical correlations were not significant, which is consistent with our previous conclusion that a single factor explains individual performance on the information processing tasks. This result should, however, be treated with caution. Canonical correlations maximize capitalization on chance fluctuations in the data. Thus .69 should be regarded as an extreme upper bound for the correlation between memory access and reading ability in college students.

Is it possible to improve the prediction of verbal performance by using an information processing task that is not heavily dependent upon speed of retrieval of information in permanent memory? This question motivated the inclusion of the sentence-picture comprehension task in the battery of tests. The multiple correlation between the Nelson-Denny reading comprehension score and two independent variables, semantic matching (the best measure of the encoding factor defined in the principal-components analysis) and sentence-picture comprehension, was $.46(\mathrm{p}<.001)$. The partial correlation between sentence-picture comprehension and reading comprehension, controlling for semantic matching, was $.31(\mathrm{p}<.02)$. Thus, the sentence-picture comprehension measure accounts for variance in reading ability that is not associated with the encoding measure. This is consistent with similar findings by Palmer et al. (Note 1) in a more extensive analysis of reading comprehension.

\section{DISCUSSION}

This experiment was designed to investigate the relationship between verbal ability and speed of access to information in long-term memory. Unlike Hogaboam and Pellegrino (1978), we found a positive relationship between verbal ability and several reaction time mea. sures. However, this experiment was not an exact replication of Hogaboam and Pellegrino's, since we were unable to use exactly the same test of verbal aptitude that they used. Carroll and Maxwell (1979) stated that it was important to resolve the discrepancy between Hogaboam and Pellegrino's results and other studies in the literature. Although, of course, this cannot be proved, perhaps the discrepancy was due to sampling fluctuations in their study having masked a phenomenon that, in absolute terms, is not a large one.

Hogaboam and Pellegrino's (1978) research was motivated by an important consideration. On the basis of results obtained using the stimulus matching paradigm, several investigators have drawn the general conclusion that there is a relationship between (written) verbal skills and speed of access to overlearned information in long-term memory. If the conclusion is sound, then a similar relationship should be found using paradigms other than stimulus matching. In the present study, such a relationship was found, both for the semantic categorization task and for the related semantic verification and semantic matching tasks. Another study in our laboratory replicated this result for semantic verification (Palmer et al., Note 1). Goldberg et al. (1977) reported positive results using a semantic matching task. Our factor-analytic results indicate that these paradigms all share a common factor that may be interpreted as speed of access to information in semantic memory. The canonical correlations (and the correlations between the Nelson-Denny measures and markers of the factor) indicate that this factor is related to individual differences in verbal ability.

Performance in a sentence-picture comprehension task also predicted reading comprehension scores, confirming similar observations by Baddeley (1968) and Lansman (Note 3). Sentence-picture comprehension has a predictive power beyond that provided by a test of retrieval of information from semantic memory. This suggests that there are at least two mechanisms of information processing involved in comprehending verbal material: retrieving the meaning of symbols and manipulating meaning in working memory.

Whether the memory retrieval factor identifiable here is the same as a factor that might be defined by tests of speed of access to information in episodic memory (i.e., whether there is a general memory-access factor) is at present an open question. There is tangential evidence that semantic and episodic retrieval factors are not identical. Underwood, Boruch, and Malmi 
(1978; see also Hunt's 1981 reanalysis of their data) have reported that episodic memory tests are not related to performance on verbal aptitude tests.

The correlations reported in this and other studies are typically in the .3 range. Verbal aptitude is defined by performance on relatively complex tasks and undoubtedly depends upon knowledge, as well as upon more mechanistic aspects of information processing, such as accessing overlearned information. Other information processing traits, including the ability to hold information in short-term memory and to focus attention, are also involved in tests of verbal ability. It would be naive to expect that any one information processing trait (let alone one paradigm) would provide the single explanation of such a complex ability. It does seem clear that the process of accessing overlearned material is one of the important individual difference variables that underlies skilled verbal performance.

\section{REFERENCE NOTES}

1. Palmer, J. C., MacLeod, C. M., Hunt, E., Davidson, J. E. Some relations between information processing and reading. Unpublished manuscript, 1981.

2. Lansman, $\bar{M}$. Paper-and-pencil measures of cognitive processes. Paper presented at the meeting of the Western Psychological Association, Seattle, April 1977.

3. Lansman, M. An attentional approach to individual differences in immediate memory (tech. rep. 2). Seattle: University of Washington, Department of Psychology, June 1978.

4. Carroll, J. B. Personal communication, December 1980.

\section{REFERENCES}

BAdDeley, A. D. A 3-minute reasoning test based on grammatical transformation. Psychonomic Science, 1968, 10, 341-342.

BADDELEY, A. D. The psychology of memory. New York: Basic Books, 1976.

Battig, W. F., \& Montague, W. E. Category norms for verbal items in 56 categories: A replication and extension of the Connecticut category norms. Journal of Experimental Psychology Monograph, 1969, 80(3, Part 2).

Carroll, J. B., \& Maxweld, S. E. Individual differences in cognitive abilities. Annual Review of Psychology, 1979, 30 , 603-640.

Clark, H. H., \& Chase, W. G. On the process of comparing sentences against pictures. Cognitive Psychology, 1972, 3, $472-517$.

Cohen, J., \& Cohen, P. Applied multiple regression/correlation analysis for the behavioral sciences (2nd ed.). Hillsdale, N.J: Erlbaum, 1975.

Goldberg, R. A., Schwartz, S., \& Stewart, M. Individual differences in cognitive processes. Journal of Educational Psychology, 1977, 69, 9-14.
Harman, H. Modern factor analysis (3rd ed.). Chicago: University of Chicago Press, 1976.

Hogaboam, T. W., \& Pellegrino, J. W. Hunting for individual differences in cognitive processes: Verbal ability and semantic processing of pictures and words. Memory \& Cognition, 1978, 6, 189-193.

Hunt, E. Mechanics of verbal ability. Psychological Review, $1978,85,109-130$.

Hunt, E. The design of a robot mind: A theoretical approach to issues in intelligence. In M. Friedman, J. P. Das, \& M. O'Connor (Eds.), Intelligence and learning. New York: Plenum, 1981.

Hunt, E., Lunneborg, C., \& Lewis, J. What does it mean to be high verbal? Cognitive Psychology, 1975, 7, 194-227.

Kučera, H., \& Francis, W. N. Computational analysis of present-day American English. Providence: Brown University Press, 1967.

Matarazzo, J. D. Wechsler's measurement and appraisal of adult intelligence (5th ed.). Baltimore, Md: Williams \& Wilkens, 1972.

Nelson, M. J., \& Denny, E. C. The Nelson-Denny reading test. Boston: Houghton Mifflin, 1960.

Posner, M. I. Chronometric explorations of mind. Hillsdale, N.J: Erlbaum, 1978.

Posner, M. I., \& Mitchell, R. F. Chronometric analysis of classification. Psychological Review, 1967, 74, 392-409.

Schwartz, S. Verbal ability, attention, and automaticity. In M. Friedman, J. P. Das, \& M. O'Connor (Eds.), Intelligence and learning. New York: Plenum, 1981.

Undenwood, B. J., Boruch, R. F., \& Malmi, R. A. Composition of episodic memory. Journal of Experimental Psychology: General, 1978, 107, 393-419.

\section{NOTES}

1. The correlations between the semantic categorization measures and the WPC verbal scores, shown in Table 5, were low and nonsignificant. It appears that the difference between these correlations and those involving the Nelson-Denny scores is due to fluctuations in small samples; when we recomputed the latter correlations using only those subjects who had WPC scores, they were also low and nonsignificant.

2. Two technical comments about our factor analysis are in order. Although the factor analysis was unaffected by removal of effects associated with choice reaction time, some method variance may still remain. This is suggested by the fact that a lower loading was obtained for the semantic categorization task, which is the only task in which different equipment was used. Although any factors beyond the first are clearly much smaller than the first factor, they may be statistically reliable. John Carroll (Note 4) has reanalyzed our data using more sophisticated factor-analytic procedures and has concluded that three factors may be reliably extracted from the data. Their relative sizes are approximately the same as those shown in our analysis. Carroll's loadings for tasks on the first factor agree with our estimates to within .05 .

(Received for publication November 3, 1980; revision accepted May 5, 1981.) 